\title{
Oral health promotion in NSW
}

\author{
Jennifer M. Noller ${ }^{\mathrm{A}}$, John C. Skinner ${ }^{\mathrm{A}, \mathrm{D}}$, \\ Anthony S. Blinkhorn ${ }^{\mathrm{B}}$ and Greer M. Dawson ${ }^{\mathrm{C}}$ \\ ${ }^{\mathrm{A}}$ Centre for Oral Health Strategy, NSW Ministry of Health \\ ${ }^{\mathrm{B}}$ Faculty of Dentistry, The University of Sydney \\ ${ }^{\mathrm{C}}$ NSW Public Health Officer Training Program, \\ NSW Ministry of Health \\ ${ }^{\mathrm{D}}$ Corresponding author.Email: john.skinner@health.nsw.gov.au
}

A healthy mouth is essential for general health and wellbeing, enabling individuals to communicate effectively, and to eat and enjoy a variety of foods. It is important for overall quality of life, self-esteem and social confidence. ${ }^{1}$ The cost of oral disease to individuals and society extends beyond the oral health burden alone; there is, for example, lost productivity due to absenteeism from work and school, and reduced quality of life. ${ }^{2}$

Dental caries and periodontal diseases have historically been considered among the most important global oral health burdens; ${ }^{3}$ these are largely preventable and reversible if identified and treated early. ${ }^{4}$ Changes in health behaviour can help prevent oral diseases: reducing the frequency of sugary food and drink intake; modifying alcohol consumption; ceasing tobacco use; drinking fluoridated tap water; brushing teeth and gums twice a day with a fluoride toothpaste; and visiting a dentist regularly. Promoting health behaviour change is not straightforward. Social and economic disadvantage strongly influence health behaviour ${ }^{5}$ and oral health status closely follows social gradients in the same way social gradients are linked to general health status. ${ }^{6}$ This highlights the need for an approach that considers not only the individual but their context, and promotes an environment where individuals can take control of their own health and wellbeing.

Although overall improvements have occurred, oral health inequalities remain a major public health challenge globally. ${ }^{7}$ There are subpopulations within the community that will need additional focus to ensure disparities in oral health status are reduced. Aboriginal and Torres Strait Islander people, older people, adults and children with special needs, children in out-of-home care, and those in rural/remote communities where access to services is limited, are priority groups in NSW. ${ }^{8}$

While advances in clinical techniques have made dental treatment more effective, treatment approaches alone will never eradicate oral diseases. ${ }^{9}$ A mix of complementary public health approaches incorporating disease prevention and health promotion is required that focus on creating supportive environments that help to sustain good health, and assisting individuals and communities to avoid oral disease. ${ }^{9}$

In NSW, oral health promotion is organised through the NSW Oral Health Promotion Network (the Network), established by the Centre for Oral Health Strategy, NSW Ministry of Health. The Network comprises oral health promotion coordinators, or their representatives, from each Local Health District (LHD) in NSW, as well as other key representatives from policy, academia, professional associations, industry, and the community. The objective of the Network is to ensure that oral health promotion efforts in NSW are collaborative, well coordinated, evidence based, and continuously delivered in an effective and efficient manner.

Oral Health 2020: A Strategic Framework for Dental Health in $N S W^{8}$ sets the platform for oral health action in NSW into the next decade. It articulates the need for shared responsibility and a partnership approach to improve the oral health of the NSW population. The development of the framework was influenced by a range of state and national oral health programs, funding initiatives, reviews and reports including the NSW Ministerial Taskforce on Dental Health, the report of the National Advisory Council on Dental Health, and Commonwealth initiatives such as the Child Dental Benefits Schedule, and the Dental National Partnership Agreement.

Oral Health 2020 has a major focus on prevention of oral disease and includes the following priority areas: water fluoridation; integrated health promotion; primary and tertiary service delivery; workforce; professional education; and data, research and evaluation. The following case studies describe three NSW initiatives that illustrate oral health promotion in action. These initiatives add value to existing prevention programs, such as water fluoridation a cost-effective measure for reducing dental caries ${ }^{10}$ that reaches $96 \%$ of the Australian population ${ }^{11}$ and one of the few public health interventions that reduces disparities in oral health between socioeconomic groups ${ }^{12}$ - and the Early Childhood Oral Health Program, ${ }^{13}$ which aims to improve the health and wellbeing of children in NSW by integrating oral health into general health interventions provided by child health professionals.

The case studies described here also capitalise on a broader health promotion agenda. The correlation between general health, lifestyle behaviours and increased risk of dental caries, periodontal disease, oral infections, oral cancer, and other oral conditions warrants an integrated approach to 
health care provision. ${ }^{14}$ Key risk factors including poor diet, smoking, alcohol, and poor hygiene can contribute to a wide range of both general and oral health complications. Oral health promotion in NSW thus uses the common risk factor approach; incorporating oral health promotion into general health promotion initiatives that target a range of chronic diseases (e.g. obesity, diabetes, cancer, cardiovascular disease and respiratory disease). For example, programs such as the NSW Healthy Children Initiative ${ }^{15}$ provide a platform for key oral health messages, such as choosing water as a drink, promoting breastfeeding, and reducing consumption of sugary drinks and food.

The paper on the Bila Munji Oral Health Promotion Partnership by Meihubers describes an integrated program serving Aboriginal communities in western and northwestern NSW. It explains the process used to identify local priorities, the range of strategies used and the oral health promotion successes achieved in the rural and remote communities of NSW where this program is delivered. The paper highlights the importance of active involvement of local staff who work with communities in the planning and implementation of Aboriginal health promotion programs. The coordinated effort, across a range of community settings and over several years, has raised the profile of oral health in the participating communities and resulted in the activities becoming embedded in the routine business of local Aboriginal Community Controlled Health Organisation, health, and community staff. The program is now shifting focus to young adults and people with chronic disease.

Targeting smoking has become an important role for oral health professionals. Tobacco smoking is the single greatest cause of premature death and is a leading preventable cause of morbidity in NSW. ${ }^{16}$ In Models of smoking cessation brief interventions in oral health, Dawson, Noller and Skinner review different approaches to smoking cessation brief interventions used by oral health professionals in Australia and internationally. This paper also introduces the evaluation of the NSW Health policy directive, Smoking cessation brief intervention at the chairside: role of public oral health/dental services, which mandates clinicians within public dental services to undertake chairside smoking cessation brief interventions. ${ }^{17}$ The review and the results of the forthcoming evaluation will inform the development of a best practice model for smoking cessation brief interventions for oral health professionals in NSW.

In An evaluation of dental information sessions provided to childcare educators in NSW in 2010-2011, Noller describes the evaluation results of one component of the NSW Little Smiles Program: dental information sessions provided to childcare educators in NSW to promote oral health and assist with accreditation requirements. Although participants' confidence in the key areas covered by the training increased, the dental information sessions were not sustainable as implemented; more cost-effective methods are required. The case study articulates future directions for strengthening the oral health skills and knowledge of childcare educators.

\section{Conclusion}

Oral health promotion has an exciting future that will require a strong partnership model between the NSW Ministry of Health, local health and education service providers, and the tertiary education and community service sectors, to address the oral health promotion priority actions in Oral Health 2020. It will also be important for NSW to continue the strong partnerships already established with oral health promotion practitioners in other Australian jurisdictions, through the National Oral Health Promotion Steering Group and the new National Oral Health Plan, which is currently in development. The three case studies presented here provide insights that will support future oral health promotion efforts in NSW.

\section{References}

1. Australian Institute of Health and Welfare. Australia's health 2008. Cat. no. AUS 99. Canberra: AIHW; 2008.

2. Hollister MC, Weintraub JA. The association of oral status with systemic health, quality of life, and economic productivity. J Dent Educ 1993; 57(12): 901-12.

3. World Health Organization. What is the burden of oral disease? Available at: http:/www.who.int/oral_health/disease_burden/ global/en/ (Cited 6 December 2013).

4. Australian Health Ministers' Advisory Council. Oral health of Australians: national planning for oral health improvement: final report. Steering Committee for National Planning for Oral Health. South Australia: AHMAC; 2001.

5. Spencer AJ, Sendziuk P, Slade G, Harford J. Chapter 9: Interpretation of findings. In: Slade GD, Spencer AJ, RobertsThompson KF (eds). Australia's dental generations: The national survey of adult oral health 2004-06. Canberra: Australian Institute of Health and Welfare Dental Statistics and Research Series No. 34; 2007. p. 237-8.

6. Watt RG. Social determinants of oral health inequalities: implications for action. Community Dent Oral Epidemiol 2012; 40(2): 44-8. doi:10.1111/j.1600-0528.2012.00719.x

7. Petersen PE. The World Oral Health Report 2003: continuous improvement of oral health in the 21 st century - the approach of the WHO Global Oral Health Programme. Community Dent Oral Epidemiol 2003; 31(Suppl 1): 3-23. doi:10.1046/j..2003. com122.x

8. NSW Ministry of Health. Oral Health 2020: A Strategic Framework for Dental Health in NSW. Sydney: NSW Ministry of Health; 2013.

9. Watt RG. Strategies and approaches in oral disease prevention and health promotion. Bull World Health Organ 2005; 83(9): 711-8.

10. Campain AC, Marino RJ, Wright FA, Harrison D, Bailey DL, Morgan MV. The impact of changing dental needs on cost savings from fluoridation. Aust Dent J 2010; 55(1): 37-44. doi:10.1111/j.1834-7819.2010.01173.x 
11. Sivaneswaran S. The revival of water fluoridation in the state of New South Wales, Australia, in the 21st century. Community Dent Oral Epidemiol 2012; 40(Suppl 2): 65-70. doi:10.1111/ j.1600-0528.2012.00722.x

12. Better Oral Health - European Platform. The state of oral health in Europe: Report commissioned by the Platform for Better Oral Health in Europe. Available at: http:// www.oralhealthplatform.eu/state-oral-health-europe (Cited 5 November 2013).

13. NSW Health. Early Childhood Oral Health Guidelines for Child Health Professionals, 2nd edition. Guideline GL2009_017. Available at: http://www0.health.nsw.gov.au/policies/gl/2009/ pdf/GL2009_017.pdf (Cited 6 December 2013).
14. Sheiham A, Watt RG. The common risk factor approach: a rational basis for promoting oral health. Community Dent Oral Epidemiol 2000; 28(6): 399-406. doi:10.1034/j.1600$0528.2000 .028006399 \mathrm{x}$

15. NSW Ministry of Health, NSW Department of Education and Communities, Heart Foundation. Healthy Kids. Available at: http://www.healthykids.nsw.gov.au/ (Cited 6 December 2013).

16. NSW Ministry of Health. NSW Tobacco Strategy 2012-2017. Sydney: NSW Ministry of Health; 2012.

17. NSW Department of Health. Smoking cessation brief intervention at the chairside: role of public oral health/dental services. Sydney: NSW Department of Health; 2009. 